\title{
Impact of Multiplex Relationships on Rural Science Education
}

\author{
Peter Knutson \\ Dawn Del Carlo
}

Relationships play a strong role in rural communities and education, and multiplex relationships-relationships that can overlap due to multiple contexts of interaction in a rural school — are unique to the rural setting. This study focused on multiplex relationships and their impact on science classroom performance, as measured by science standardized test scores, through the lens of Social Capital Theory. Quantitative survey results from rural science teachers regarding number of student relationships and state-based science test scores were correlated. Additionally, qualitative survey answers from a subset of respondents were used to construct a more complete picture of the essence of these relationships and their perceived impacts. Results indicate multiplex relationships do not impact science test score achievement; however, teacher accounts of classroom experiences with students illustrate a strong perception that multiplex relationships increase their ability to help students succeed.

\section{Background}

Rural schools are a unique blend of community, geography, and people, and it is these distinctive features that provide the structure around which the rural educational experience is molded. Inexorably the people who live in these communities are interconnected, and the lines between the community at-large and the school are oftentimes blurred, creating an interdependent environment that influences education. Rural settings invite intimacy, allowing for more closely monitored progress of a student's education (Barley \& Beesley, 2007; Klem $\&$ Connell, 2004). Focus by multiple members in the student's educational path provide a substantial, enriching, and effective educational experience unique to a rural educational setting. This experience and the framework it forms is due in large part to the participation of multiple individuals who hold multiple roles in the students' lives (Campbell \& Gordon, 2003; Klem \& Connell, 2004). These 'multiplex relationships' are personal connections that span multiple levels of familiarity, contact, roles, and influence (Coleman, 1988; Gluckman, 1967; Goodpaster, Adedokun, \& Weaver, 2012).

Previous studies on the rural education experience often focus on the relationship between students and teachers (Aultman, Williams-Johnson, \& Schutz, 2009; Carr, 2005; Hardré, Sullivan \& Roberts, 2008; Reyes, et al., 2012; Roorda, et al., 2011), peer-peer relationships (Gristy, 2012), or the relationship between school personnel and community members (Alleman \& Holly, 2013; Tytler et al., 2008). However, there is a lack of research focusing on the interconnectivity of multiplex relationships in rural schools that extend beyond the abovementioned relationships. Current research is additionally limited on the impact that multiplex relationships have on teacher perceptions of the rural education experience. Finally, a gap exists in the exploration of the impact multiplex relationships specifically have on performance in the science, technology, engineering, math (STEM) and other related fields. Understanding the effect of multiplex relationships on science classroom performance and engagement in rural and smaller schools will aid in the larger understanding of the role of relationships in fostering entrance into emergent science career fields.

The purpose of this mixed method study is to explore whether multiplex relationships directly impact science classroom performance, as measured by the science strand of state-based standardized test scores and explore the impact multiplex relationships have on teacher perceptions of the rural science education experience.

\section{Multiplex Relationships}

The term 'multiplex relationships' was first used by Gluckman (1967) to describe the complex, overlapping relationships among tribe members in Rhodesia that span both politics and kinship, and differentiate them from simplex relationships, which are confined to independent and direct relationships. From this initial instance, the concept of this overlapping network of connections and relationships entered the nomenclature and literature of sociology. Multiplex relationships can describe a situation where "persons are linked in more than one context (neighbor, fellow worker, fellow parent, coreligionist, etc.)" (Coleman, 1988, p. S109). As such, the study of multiplex relationships is fundamentally different than that of "Teacher-Student Relationships where the focus is predominantly on teacher characteristics, 
like empathy, or interactions that occur in the context of the classroom" (McCormick, et al., 2013; Roorda, et al., 2011; Spilt et al., 2012). Multiplex relationships are unique in that they extend beyond the professional confines of the classroom and into the personal lives of the students and teachers. The very nature of the rural community and the school within leads to an extensive network of these multiplex relationships and set rural schools apart from urban and suburban locations.

\section{Multiplex Relationships in Rural Schools}

Multiplex relationships are common in rural community schools where a student's teacher may also be her volleyball coach, and friends with the student's parent (Goodpaster et al., 2012). The multilevel and interconnected relationships in both the personal and professional contexts specifically characterize the rural experience where a familial culture including trust and intimacy are the cornerstones of the school climate (Hargrove, 1986; Huysman, 2008). It is this culture and the subsequently created relationships that build connectedness to the school and invest both student and teacher in the success of the institution (Barley \& Beesley, 2007; Lake, 2008).

There is also a connection between rural school culture, founded on these close student-teacher relationships, and individual achievement in the classroom (Carr, 2005; Hardré et al., 2008, Horn, 1995; Matthew, 1995). Rural schools tend to have a culture and climate that is familial, which promotes support and intimacy (Berry \& Gravelle, 2013) and does not necessarily cease at the school doors or at the end of the school day (Huysman, 2008). This tightknit school environment is a unique feature of rural education and with positive teacher-student relationships, can strengthen classroom performance (Berry \& Gravelle, 2013; Carr, 2005; Hardré et al., 2008; Klem \& Connell, 2004; Roorda, et al., 2011). Within such an intimate environment, personal relationships are constructed and build trust between students, parents, teachers, administrators and members of the community and it is these relationships that are distinguishing of the rural education experience (Goodpaster et al., 2012). However, most previous studies examined student achievement as an outcome of the Teacher-Student relationship in the context of the classroom environment (McCormick, et al., 2013; Roorda, et al., 2011; Spilt, et al., 2012), rather than as a network that extends beyond the classroom and into the personal spaces of both the teacher and the student. Multiplex relationships account for all possible social interactions between teachers and students, not just those that occur in the classroom, and as such, are a more appropriate measure for a rural setting where the lines between "school" and -home" are blurred (Berry \& Gravelle, 2013; Huysman, 2008).

\section{Rural Science Education}

Science in a rural school setting is unique in both its execution and curricular opportunities and comes with its own set of benefits and logistical difficulties. Rural science classrooms have fewer students in them, thereby increasing specialized attention in the material and in labs (Colton, 1981). In addition to limited curriculum due to fewer course offerings and materials and diminished financial support (Horn, 1995; Sipple \& Brent, 2008), rural students struggle to connect the "academic science" to their everyday lives, despite the multitudinous examples that surround them (Avery \& Kassam, 2011; Avery, 2013; Edmondson \& Butler, 2010). Opportunity to explicitly make those connections are available in the rural setting, but it takes creativity on the part of the teacher (Matthew, 1995).

Community liaisons from commerce, industry, and environmental sectors can be strongly involved in the science classroom if the teachers capitalize on community ties (Goodpaster et al., 2012; Kenny, Seen, \& Pursor, 2008; Lake, 2008). Successful agriculture teachers establish programs with a large community involvement and maintain collaborative relationships with community business members (Roberts et al., 2006). It is reasonable to extend these basic principles to science teachers and classrooms where multiplex relationships open access to available community resources which can help teachers establish the relevancy of science concepts to their students. Strong connections between schools and communities build "semi-formal" relationships which increases knowledge of resources available to teachers as well as minimizes barriers to capitalizing on those resources (Bauch, 2011; Lake, 2008). These semi-formal relationships are essential in utilizing a teacher's social capital obtain resources and provide for their students. Rural communities typically have large amounts of social capital due to the quantity and strength of relationships found there (Elder \& Conger, 2000). Students and their families in rural schools are connected with many social networks and school personnel utilize their own connection to these networks, or social capital, to promote positive school or district initiatives (Alleman \& Holly, 2013; Lake 2008). 


\section{Theoretical Framework and Research Questions}

\section{Social Capital Theory}

Social Capital Theory is a framework in which individuals and the power of their relationships are essential in the construction of action. Coleman's (1988) model of social capital creates an awareness of a multiplex relationship's role in the success within the educational sphere. Within the educational setting, certain norms are indicative of its structure and expectations. These norms, such the desire for student achievement, are supported by social interaction and resultant obligation to those with whom one maintains a relationship and are further reinforced by strong family obligations and interests (Coleman, 1988; Howley, A., Howley, M., Camper, C., \& Perko, H., 2011). Furthermore, Coleman's model indicates there are two types of social networks: without closure (no commonality between all members of the network) and with closure (interconnected and multiplex relationship[s] within the network). Closed networks, much like isolated rural communities, create social capital based on the trust built between the members of the network, and propagates the community norms and expectations. (Coleman, 1988; ). Rural communities create strong, multiplex relationships (Campbell \& Gordon, 2003; Goodpaster et al., 2012; Hargrove, 1986), which help to create a strong sense of community itself (Barley $\&$ Beesley, 2007). These relationships, which are established through social interaction, promote mutual trust and foster collaboration within the community and therefore generate social capital (Bauch, 2001; Elder \& Conger 2000).

An expectation of reciprocity in deeds, goods, time, etc. is rooted in the trust forged in strong relations and assists in maintaining the productivity of the relationship itself (Western, Stimson, Baum \& Von Gellecum, 2005). The transfer of these trustbased assistances in a social network are a form of social capital, and if it is a closed social structure, the amount of social capital in that network will increase further (Coleman, 1988). The more 'closed' a network is, the stronger the social capital will be, and the multiplex relationship helps to tighten the network's interconnectivity, thereby increasing trust, and subsequently social capital. The rural community meets criteria for high levels of social capital established by Coleman (1988) and Western et al. (2005) in that they contain relationships that are high in trust and exist in closed structures, and therefore are relationships capable of productivity. Rural communities epitomize the connection to place and are built on community member participation in community initiatives. Elder and Conger (2000) suggest community member leadership in extracurricular and community linked activities provides social capital for the community, fostering the development of youth.

Studies found that within the rural setting, strong relationships emerge due to the tight-knit structure, and these relationships are utilized for success in the classroom. In rural settings, individuals who interact with children establish social capital through relationships with others who also interact with children, strengthening the individual's own ability to foster growth in children (Elder \& Conger, 2000). Although much of the literature regarding multiplex relationships concentrate on the social capital generated for economic or social network gains or reciprocity, there is precedence in connecting it to the exploration of social capital in children. In the current study, the multiplex relationships explored are those established in the rural science classroom. If multiplex relationships are known to be strong relationships as they accrue large amounts of social capital, and relationships in schools, especially rural schools, can be linked to classroom success (Carr, 2005; Hardré et al., 2008, Horn, 1995, Matthew, 1995), then multiplex relationships could also possibly increase that success, and thereby should be researched further.

\section{Research Questions}

Multiplex relationships are often viewed in economic and social contexts. Although it is mentioned within the rural education context, few studies have explored the academic impact of multiplex relationships, as opposed to classroom environment, explicitly in schools. Gaps remain in the literature surrounding the effect multiplex relationships have on both actual and perceived classroom performance, specifically with regard to rural science education. As such, we seek to understand:

1. If a teacher's multiplex relationships are positively correlated with academic performance in the rural science classroom?

2. How do teachers' social capital influence their perceptions of the rural science education experience?

\section{Methods}

\section{Recruitment}

School district, teacher names and other demographic information were collected from publicly available information on the Iowa State Department of Education (IDOE) website. Schools 


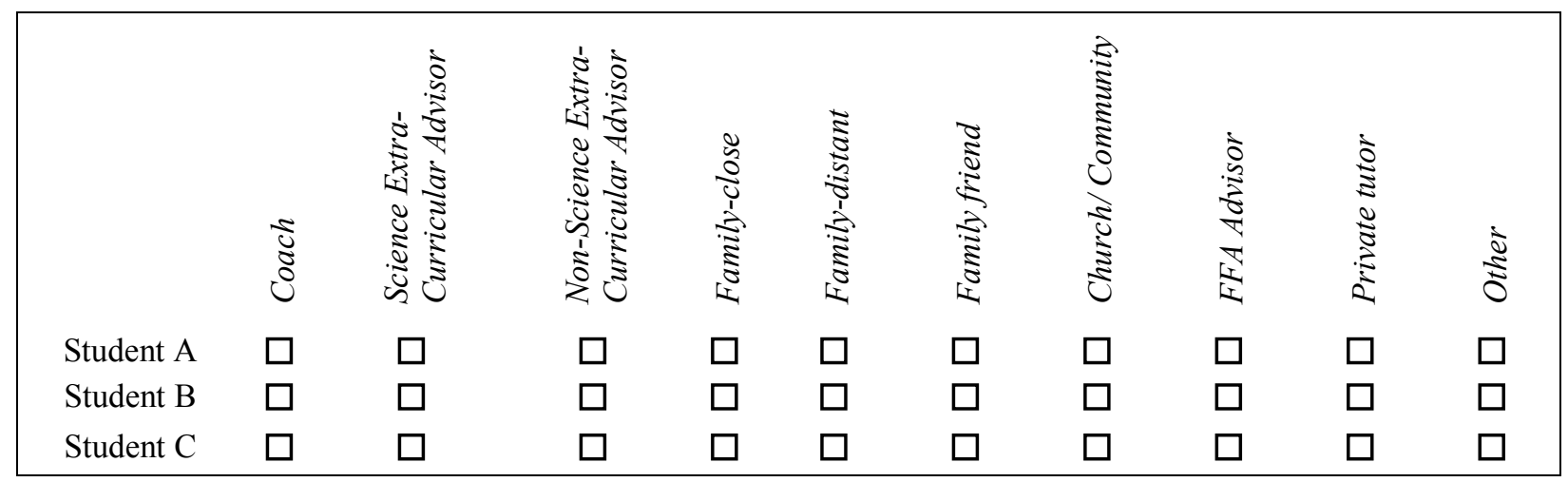

Figure 1: Example Relationship Grid Assuming a Class Size of Three Students

were classified as rural if enrollment fell within the lowest quartile ( $<100$ students per grade) and met the Census Bureau's definition of rural based on location (> 2.5 miles from urban center) (National Center for Education Statistics, 2006). A total of 243 schools in the state of Iowa met these criteria and were selected as schools from which participants were recruited. The names of secondary (grades 7-12) teachers listed under each rural school on the IDOE website were collected and designated as "science teachers" if they were listed under the science department on their district/school website or if they had an explicit science course listed in conjunction with their name (i.e. " $7^{\text {th }}$ grade science" or "chemistry"). Agricultural education teachers or FFA advisors were not included in the participant pool. This resulted in a pool of 694 rural science teacher participants. Teachers were invited to participate in the study via their publicly listed email address.

\section{Data Collection}

The study was conducted using a mixed method, explanatory sequential design (Creswell, 2013). Quantitative data in the form of state standardized test scores and teacher-reported teacher-student relationship status were collected and analyzed first followed by the qualitative data collection and analysis. !uantitative data were used to explore the relationship between multiplex relationships and science classroom performance, whereas the qualitative data were used to explore teachers' perceptions regarding the impact of multiplex relationships on student performance in the classroom.

Test Scores. In the State of Iowa, the Iowa Testing Program (ITP) is the annual standardized test that is administered to Iowa students, $\mathrm{K}-12$, in the core subjects of reading, writing, mathematics, social studies, and science. Raw science scores and proficiencies from the ITP in grades 7, 8 and 11 were obtained directly from the State of Iowa DOE website. Results were filtered such that only scores from schools designated as "rural" in this study were collected and were from the same academic year as the questionnaire data. The ITP score, although limited in describing all classroom successes or failures, represents a measure of academic achievement for the scope of this study.

Relationship Questionnaire (RQ). The purpose of the Relationship Questionnaire (RQ) was to obtain information about the types and extent of multiplex relationships science teacher participants establish with their students. Participants were asked to individually identify the number and type of relationship they had with each of the students on their $3^{\text {rd }}$ period class roster in a "relationship grid" (Figure 1). The most common type of relationships as established in the literature - were listed in a "select all that apply" format and included: coach/athlete, science-based extracurricular advisor, non-science activity advisor, FFA advisor, family (close/extended), family (distant), family friend, church or community organization, and private tutoring/lessons (Aultman et al., 2009; Barley \& Bessley, 2007; Brown, 2002; Carr, 2005; Guest \& Schneider, 2003; Lake, 2008; Lock, 2008; Ludden, 2011; Frankovits, 1990; Osborn, 2012; Phelps et al., 2012; Rayfield et al., 2008; Verbrugge, 1979; Voyles, 2012). A separate text box was provided at the bottom of the grid for participants who indicated "other" to specify the nature of their relationship.

In addition to the relationship selection grid, participants were asked to rank (5-point Likert) their perception of how multiplex relationships affect science classroom performance. Demographic questions were included to obtain data on their years of service, extracurricular activities they advise, number and type of science classes taught, and rural education background. This provided the ability to compare teacher characteristics and number of multiplex relationships. Finally, participants were 
asked to indicate their willingness to participate in the next phase of the study which consisted of an essay-based "perception questionnaire" to explore their perceptions more in-depth.

Perception Questionnaire (PQ). While the RQ asked teachers to quantify their multiplex relationships and their perception of its effect on student performance, the Perception Questionnaire (PQ) was designed to gain a detailed understanding of the relationships teachers established with 3 specific students and the perceived impact of these relationships on the students. Participants who completed this more extensive questionnaire were asked to identify and compare students in their classroom who fit one of three categories: (1) a student whom they know only from their classroom (Students A), (2) a student whom they know from their classroom and one other relationship context (Student B), and (3) a student who they know from their classroom and at least two other relationship contexts (Student C). With these three students in mind, participants were asked to complete two 10point scaled ratings on each of the students. The first scale represented how the teacher would rate the level of closeness with each student, the second scale represented how much they perceived that their relationship with each student impacted the student's academic performance in the classroom. After the scaled questions, participants wrote detailed essays, further outlining their perceptions of the relationship with each student and the perceived impact of the relationship on student academic performance and participation, extracurricular participation, and the overall well-being of the student. Additional questions unique to each participant were added as follow up questions to answers from the RQ. These questions further explored participants' connection to their school and how it affected their perception of the rural education experience and multiplex relationships in the context of their own specific situations.

\section{Analysis}

Multiplex Relationship Average. Calculation of a Multiplex Relationship Average (RA) was used as the principle form of measure in quantifying the strength of a relationship between students and the teacher. RA was based on the number of relationships individual teachers reported on their RQ relationship selection grid with each $3^{\text {rd }}$ period student and calculated using following formula:

$$
R A=\frac{\left(\mathrm{m}_{1}+\mathrm{m}_{2}+\mathrm{m}_{3}+\cdots+\mathrm{m}_{n}\right)}{\mathrm{n}}+1
$$

where $m$ is the number of relationships outside the classroom with each student and $n$ is the total number of students in the class. A value of 1 was added to the result to account for the assumed base relationship of student and teacher in the context of the $3^{\text {rd }}$ period class. For example, assume a class size of 4 students. The teacher of this class knows Student \#1 through church and as someone they tutor. Consequently, m1 $=2$. Student $\# 2$ is not known outside the context of this class so $\mathrm{m}_{2}=0$; Student \#3 is a family friend, in the 4-H club which the teacher advises, and on the soccer team the teacher coaches, so $\mathrm{m}_{3}=3$; finally, Student \#4 is friends with the teacher's child so $\mathrm{m}_{4}=$ 1. Consequently, this teacher's RA would be calculated as follows:

$$
R A=\frac{2+0+3+1}{4}+1=2.5
$$

ITP Test Scores. ITP data were obtained directly from the State of Iowa Education Department and filtered to include only those schools from the RQ participant pool. Additionally, participants on the RQ were asked to identify their school and list the grades and subject areas they taught. As such it was possible to filter participant RAs by specific grade taught and correlate those RAs directly to the state reported average ITP scores for a specific grade $(7,8$, or 11) and school using the Pearson product-moment correlation coefficient $(r)$. In the collection of participant emails, it was noted that no one participating school employed more than 3 science teachers in grades 7-12 and no two teachers taught the same grade-specific course (e.g. only one teacher at the school taught all grade 8 sections). As such, it was assumed that the reported ITP score for a specific grade and school is associated with a single participating teacher and so we were able to match ITP scores with specific teacher participants. Correlations were calculated between RA and raw science scores, as well as between RA and proficiency distributions for all three grades.

Likert Scaled Questions. Two scaled questions asked participants to rank on either a 5point (RQ) or 10-point (PQ) scale how they perceived relationships with students impacted academic performance. A frequency distribution of answers from the 5-point RQ question was used to determine an overall perception from participants and ascertain if further exploration was warranted. The second 10-point PQ question, which asked participants to rank the effect their relationship had on each of three students, was analyzed using a single-factor ANOVA, despite the small sample size, because participant variables were independent from each other, with no statistical outliers, and 
approximately equal sample sizes (Northwestern, 2016). A similar analysis was performed with the answers to the PQ question that asked teachers to rank the strength of their relationship with each of the three selected students to determine if there was indeed a perceived relationship difference between the groups of selected students.

Qualitative Analysis. Essay responses were inductively analyzed using the constant comparative method (Glaser \& Strauss, 1967) and then used in a cross-case analysis across the individual student relationship classifications (A, B, or C) (Miles \& Huberman, 1994). All responses were initially read on a cursory level to get a general sense of their timbre before returning to them one by one for deeper analysis. A preliminary set of codes emerged from common words and short phrases in participant answers and was used as a starting point for a more in-depth reading and coding process. After the preliminary list of codes was generated, each participant's response was then re-read and segments of text describing aspects of the teacher-student relationship were inductively coded. Codes were added and refined as analysis continued and segments of text re-coded as necessary. Content of the codes was further analyzed and individual codes were grouped into larger five categories including, Student Engagement, Understanding Student, Approachable Teacher, No Relationship Inhibits, and Successful Regardless. Finally, responses pertaining to each student's relationship classification $(\mathrm{A}, \mathrm{B}$, or $\mathrm{C})$ were

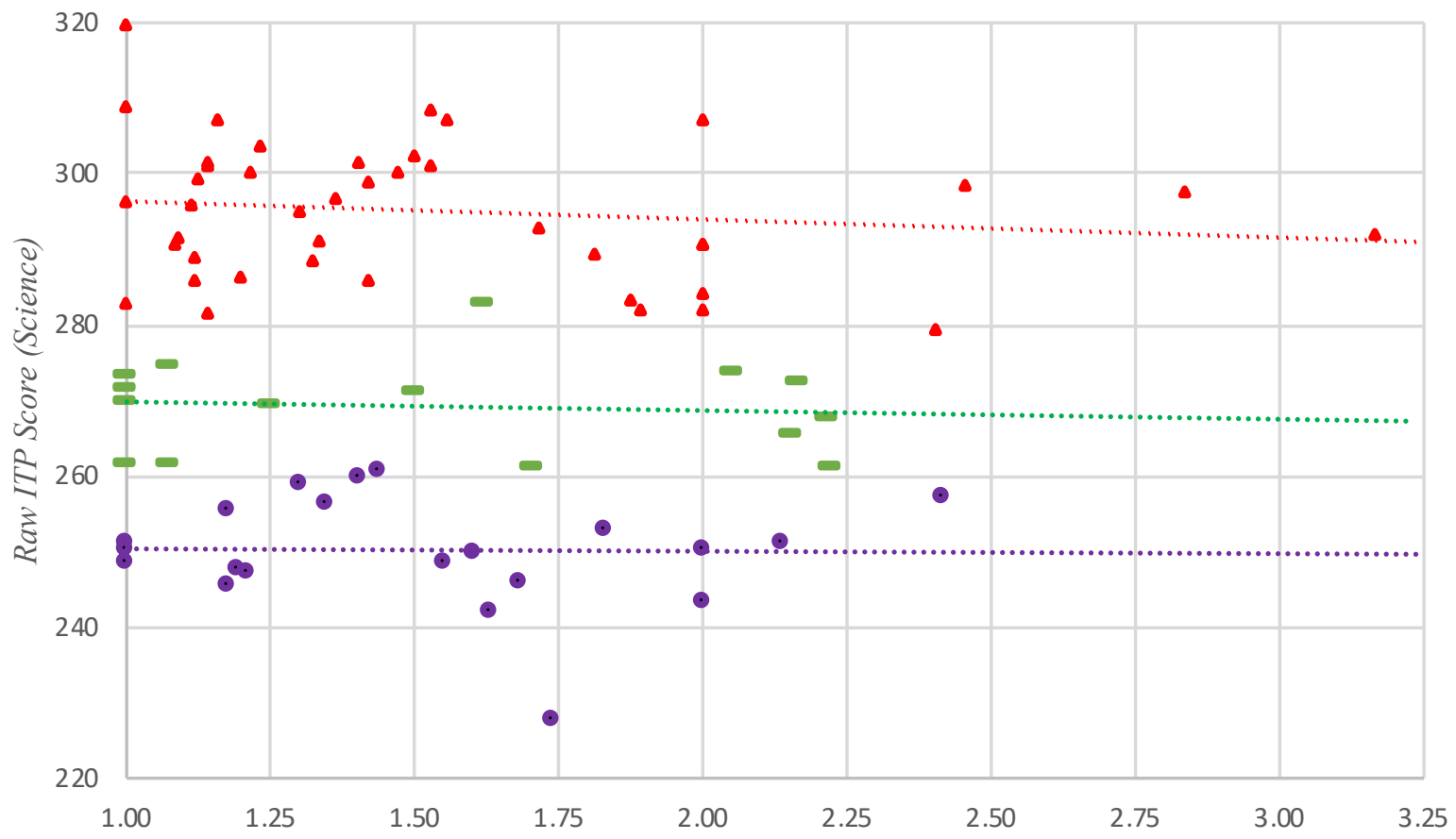

Relationship Average (RA)

- 7th Grade

- 8th Grade

- 11th Grade

$r(22)=-0.03 \quad r(16)=-0.10 \quad r(43)=-0.17$

Figure 2: Raw ITP Science Scores and RA 
Table 1

Summary of ranked questions (1-10) on the $P Q$ regarding perceived relationships strength and impact on academic performance $n=16$

\begin{tabular}{lcccc}
\hline & & Student & & p-value \\
\cline { 2 - 4 } & $\mathrm{A}$ & $\mathrm{B}$ & $\mathrm{C}$ & (ANOVA) \\
\cline { 2 - 5 } $\begin{array}{l}\text { Mean perceived relationship strength of selected } \\
\text { students }\end{array}$ & 4.7 & 7.1 & 8.1 & $<0.000$ \\
$\begin{array}{l}\text { Mean perceived impact of relationship on selected } \\
\text { student's academic performance }\end{array}$ & 5.3 & 7.1 & 7.1 & 0.025 \\
\hline
\end{tabular}

separated from one another while also maintaining the integrity of their category assignments. This allowed us to analyze the content of the previously assigned categories within each relationship classification and compare them across each group. The frequency of occurrence for each category was tabulated for each relationship classification as another basis for comparison; however, these frequencies were used in conjunction with the content of the participant responses for each classification to build a deep understanding of participants' perceptions of multiplex relationships, academic achievement of their students, and rural education.

\section{Results}

The RQ was sent to a total of 694 grade 7-12 Iowa science teachers. Twenty-four of the emails were rejected as invalid addresses, and 135 of the remaining participants completed the survey for a $20.1 \%$ response rate. Of these, $16(11.8 \%)$ opted to complete the PQ. Respondents represented 161 school buildings which according to publicly available demographic information comprised an average student body that was $91.4 \%$ Caucasian and slightly more represented by male students (51.9\%) (Iowa Department of Education, 2015). The largest ethnic minority represented was Hispanic at 5.35\% which is representative of the changing demographics of the state (State Data Center of Iowa, 2017). Within the context of the $3^{\text {rd }}$ period relationship grid, teachers described their relationship with a total of 2150 students and reported 3276 total relationships. RAs for each teacher ranged from 1.00 (having no relationship with student beyond classroom) to 3.94 (knowing their students on average in 3 contexts beyond the classroom). The median relationship average was 1.36 and the mean was 1.53 relationships per student.

\section{Research Question \#1: Multiplex Relationships and Student Achievement}

Only 81 of the $135(60 \%)$ of the RQ respondents could be directly linked to a specific grade level and therefore correlated with raw ITP science scores from their corresponding school. None of the grade levels showed any significant correlation between the relationship average and their raw ITP science score (Figure 2). Student performance on the ITP test is also measured by the percentage of students at each school whose scores falls in one of three categories: Below Proficient, Proficient, and Exceeds Proficiency. Proficiency scores classifications were also correlated with RA by grade level with small to no correlation found (Table 1).

As with the comparison to the raw ITP scores, the proficiency distribution showed low correlation values to relationship average. There were a few instances of a mild relationship between the variables, however, individual plots exhibited similar scattering to that in Figure 2. As such, correlation is not strong enough to conclude that RA impacts raw ITP science scores or proficiency.

\section{Research Question \#2: Teacher Perspectives on Multiplex Relationships and Rural Science Education}

Teachers overwhelmingly indicated that they perceived that a multiplex relationship increased student performance. Over $75 \%(n=135)$ of RQ participants indicated that they either agreed or

Table 2

Correlation between proficiency frequency and $R A$

\begin{tabular}{lcccc}
\hline Grade & $\mathrm{n}$ & \multicolumn{3}{c}{ Correlation coefficient $(r)$ between RA and student proficiency } \\
\cline { 3 - 5 } & & Below Proficient & Proficient & Exceeds Proficiency \\
\hline 7 & 22 & -0.09 & 0.23 & -0.17 \\
8 & 16 & -0.34 & 0.26 & -0.12 \\
11 & 43 & 0.04 & 0.24 & -0.26 \\
\hline
\end{tabular}


strongly agreed that "having multiplex relationships with a student increases their academic performance in the classroom" (Figure 3 ). Only 15\% were undecided about the effect and less than 7\% disagreed or strongly disagreed. What is not clear, however, is whether those who disagreed perceived no effect or a negative effect on academic performance. As such, this was explored further on the follow up PQ.

Participants who completed the more elaborate PQ were first asked to identify 3 students, rank (scale of 1-10) the perceived strength of their relationship with each student, and then also rank the perceived impact their relationship had on each student's academic performance. Single-factor ANOVA yielded statistically significant different means between groups of students $(\mathrm{F}(2,43)=16.05, \mathrm{p}=$ $\left.0.0000062, \eta^{2}=0.427\right)$ indicating that participants clearly distinguished the strength of their relationship with each of the 3 selected students with a general increase in average relationship strength as the number relationship contexts increased (Table 2). Additionally, teachers were asked to rank the impact they felt their relationship had on each student's academic performance. Again, a single-factor ANOVA indicated that there was a difference in perceived impact, but only between Student A (known only in the classroom) and Students B and C (known in contexts both in and out of the classroom) $\left(\mathrm{F}(2,43)=4.01, \mathrm{p}=0.025, \eta^{2}=0.158\right)$.

Overall, both sample sets indicated that there is an overall perception that a student's academic performance is more positively impacted as the multiplexity of the relationship between the teacher and student increases. However, the essay answers provide a bit more insight into why that perception exists.

In the essay portion of the PQ, teachers were asked to compare and elaborate on the relationships they had with each of the three identified students specifically with regard to their perception of how their relationship affected the student's academic performance. Analysis of participant answers regarding each of the 3 identified students resulted in 5 categories pertaining to teachers' perceptions of their relationship with these students: Student Engagement, Approachable Teacher, Understanding Student, No Relationship Inhibits, and Successful Regardless. Segments of participant answers about each student were classified under each category and tallied to compare across students. Table 3 lists each category, how it was defined, an example participant answer that fell under that category and the frequency of occurrences of that category in each of the types of student.

Overall, and not surprisingly, teachers more frequently expressed increased levels of student engagement and a deeper understanding of the student for the students they knew outside the context of just the classroom. Many teachers commented on how the two ideas were intimately linked, where understanding the whole student lead to increased levels of engagement both inside and outside of class:

Figure 3. Teacher Perceptions of Multiplex Relationships

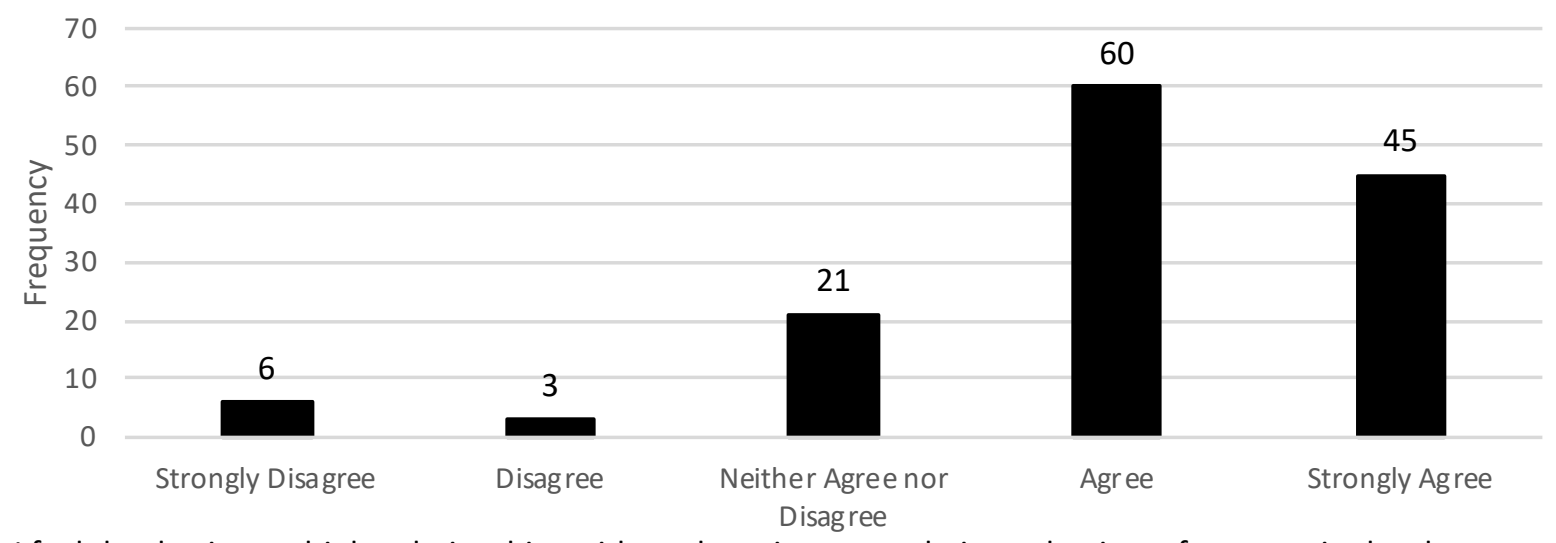

- I feel that having multiple relationships with students increases their academic performance in the classroom 
Table 3

Categories, definition, examples and frequencies for teachers perceived effects of MR

Category Definition

Example text

Student

\begin{tabular}{|c|c|c|c|c|c|}
\hline & & & A & B & $\mathrm{C}$ \\
\hline $\begin{array}{l}\text { Student } \\
\text { Engagement }\end{array}$ & $\begin{array}{l}\text { Relationship with student increases } \\
\text { student classroom performance, } \\
\text { participation, social capital, and } \\
\text { assistance to teacher }\end{array}$ & $\begin{array}{l}\text { "I do think that Jacob is more } \\
\text { receptive to some prompting by me } \\
\text { because of our positive } \\
\text { relationship." }\end{array}$ & 5 & 6 & 9 \\
\hline $\begin{array}{l}\text { Understanding } \\
\text { Student }\end{array}$ & $\begin{array}{l}\text { Relationship allows for deeper } \\
\text { knowledge of student and their } \\
\text { extracurricular participation, personal } \\
\text { life, and family }\end{array}$ & $\begin{array}{l}\text { "She often felt as though she did } \\
\text { not "measure up" to her mother's } \\
\text { standards, but I assured her that } \\
\text { her mother spoke of her with great } \\
\text { pride. I think that helped her } \\
\text { relationship with her mom" }\end{array}$ & 4 & 7 & 6 \\
\hline $\begin{array}{l}\text { Approachable } \\
\text { Teacher }\end{array}$ & $\begin{array}{l}\text { Relationship allows teacher to be } \\
\text { approachable or sought for assistance } \\
\text { by student }\end{array}$ & $\begin{array}{l}\text { "I have very close relationships } \\
\text { with some of my students and they } \\
\text { feel they can come to me for help } \\
\text { both in and [o] ut of school." }\end{array}$ & 5 & 4 & 2 \\
\hline $\begin{array}{l}\text { No } \\
\text { Relationship } \\
\text { Inhibits }\end{array}$ & $\begin{array}{l}\text { Lack of relationship with student } \\
\text { inhibits effect on student work } \\
\text { production }\end{array}$ & $\begin{array}{c}\text { "At times, we have a good working } \\
\text { relationship, but it is never } \\
\text { enduring. His participation is very } \\
\text { minimal." }\end{array}$ & 3 & 0 & 0 \\
\hline $\begin{array}{l}\text { Successful } \\
\text { Regardless }\end{array}$ & $\begin{array}{l}\text { Student, due to personal } \\
\text { characteristics will be successful with } \\
\text { or without a relationship }\end{array}$ & $\begin{array}{l}\text { "I don't feel like my relationship } \\
\text { with Matt affected his performance } \\
\text { at all. He is self-motivated." }\end{array}$ & 2 & 2 & 1 \\
\hline
\end{tabular}

I know Student $\mathrm{C}$ as her classroom teacher, speech coach, and National Honor Society Sponsor. I have also known Student C for a long time because her mother works with me. I feel that I have a very close relationship with Student C. I also think that the relationship that I had with her encouraged her to participate even more in the extra-curricular activities I am involved with.

The level of engagement and interactions, while more frequent for the more connected relationships, is perceived to be connected to academic performance:

In terms of contact, I only see Student A in class daily, but I do make a point to talk to her specifically each day in class. Her grade in my course is directly related to how much I interact with her.

Together, these categories translate into teachers' perceptions of improved academic performance with increased interaction and engagement with their students. One teacher sums it up nicely by saying: I feel that having that relationship outside of the classroom has impacted how well the students in my class work and how the students respond in my classroom. With not being able to build that relationship with Student A, it has been harder to get him interested and involved in class.

Interestingly, this increased level of engagement did not actually translate to an increased response frequency of teachers being more approachable to the student they felt more connected to. However, in examining the context of the Approachable Teacher category, teachers often cited the fact that students still came in to talk with them despite the lack of a deep relationship. For example, one teacher describes Student A by saying, "[I] only have [Student A] in class; still feels comfortable to come in and ask for help and to get missing work." Rather than expressing an increase in approachability due to a more connected relationship, teachers are citing their perceived approachability as a "baseline" interaction with the students they only know in the context of the classroom. As the relationship complexity increases across Students B and C, teacher approachability is mentioned less frequently as other contexts and interactions increase.

However, despite the baseline interaction of seeking additional help mentioned by some teachers, others felt that their smaller number of interactions with Student A actually inhibited the student's performance. One teacher stated:

I do not interact with Student A outside of the classroom setting and she was the one who struggled the most in Chemistry. She would 
Table 4

Categories, definition, examples and frequencies for characteristics of $M R$

\begin{tabular}{|c|c|c|c|}
\hline Category & Definition & Example text & Frequency \\
\hline $\begin{array}{l}\text { Student } \\
\text { Engagement, } \\
\text { Recruitment }\end{array}$ & $\begin{array}{l}\text { Relationship with student } \\
\text { increases student classroom } \\
\text { performance, participation, } \\
\text { recruitment into extracurricular } \\
\text { activities, social capital, and } \\
\text { assistance to teacher }\end{array}$ & $\begin{array}{l}\text { "I like that I know the students well and I } \\
\text { feel like they try harder in my classes." } \\
\text { "I have been trying to recruit for my } \\
\text { extracurricular and I find that students } \\
\text { that like me in the classroom are more } \\
\text { likely to go out for that activity." }\end{array}$ & 14 \\
\hline $\begin{array}{l}\text { Understanding } \\
\text { Student }\end{array}$ & $\begin{array}{l}\text { Relationship allows for deeper } \\
\text { knowledge of student and their } \\
\text { extracurricular participation, } \\
\text { personal life, and family }\end{array}$ & $\begin{array}{c}\text { "I like developing a full relationship with } \\
\text { my students, and it is easier to do this } \\
\text { when I also have relationships with their } \\
\text { family members." }\end{array}$ & 14 \\
\hline Informalities & $\begin{array}{l}\text { Relationship has a negative } \\
\text { impact due to the informalities } \\
\text { that can arise }\end{array}$ & $\begin{array}{l}\text { "Sometimes is it difficult for them to } \\
\text { separate relationship from how the } \\
\text { classroom relationship needs to work." }\end{array}$ & 7 \\
\hline $\begin{array}{l}\text { Families Taking } \\
\text { Advantage }\end{array}$ & $\begin{array}{l}\text { Relationship has a negative } \\
\text { impact due to students and/or } \\
\text { families can take advantage }\end{array}$ & $\begin{array}{l}\text { "I also dislike when students/parents use } \\
\text { relationships to manipulate school } \\
\text { professionals to get what they want." }\end{array}$ & 2 \\
\hline
\end{tabular}

sometimes come for extra help/instruction but it was rare and often forced by her mother.

While it is entirely possible that this student would not come in for extra help even if she had a closer relationship with the teacher, it appears this teacher does not perceive that to be the caseFinally, a number of teachers felt their selected students were academically successful regardless of their relationship. This applied to all three types of students depending on who the individual teachers selected. For example, one teacher indicated, "Student A is a great student and involved in everything. I believe my relationship has had no real impact on her academics or participation in extracurricular activities." However, a different teacher expressed, "Student B consistently participates even when other classmates may lack motivation to do so. I think our relationship may enhance this, but I don't think it causes her participation." Teachers recognize that while they perceive their relationships impact the academic performance of some students, other students already have the support structures in place to be academically successful.

Additionally, teachers were asked to describe the characteristics of their multiplex student relationships and comment on what they liked and disliked about those characteristics. Analysis of participant answers resulted in another 4 categories: Student Engagement and Recruitment, Understanding Student, Increased Recruitment, Informalities and Families Taking Advantage. Table 4 lists each category, how it was defined, an example participant answer that fell under that category and the frequency of occurrences of that category found in participant answers.

Similar to the comments gleaned from the student comparisons, the most frequent and positive characteristics of multiplex relationships cited by participants are an increased sense of engagement from the students and a knowledge of the student as a whole person. Many teachers commented on how their relationships with students enhanced the classroom environment because they can better individualize instruction. For example:

Knowing the students helps to know what they can and can't do in the classroom. The multiplex relationship helps teachers make adjustments in instruction to better cater to a student's needs. Another teacher stated that she liked the fact that relationships with students allow her to make the content of class more relatable because she knows the students' interests better:

I also am able to build a better relationship with those students during other activities and find out their interests. I can then apply that to my science class to help them understand material and concepts on a higher level.

This knowledge and understanding of the student extends far beyond the confines of the classroom and provides teachers with a better context to help students succeed. One teacher stated:

I like [multiplex relationships] because it allows me to understand what the student is dragging into class with them as well as seeing all sides to 
that student - how they are in my class may not be how they are on the court, or in church, etc. This allows for more personalization of interests for projects as well as making decisions how best to help that student cope.

Ultimately, the biggest advantage perceived by rural teachers is the fact that they are able to educate and mentor the "whole child". For many teachers, their job extends beyond the classroom and into all aspects of their students' lives, which then feeds back into the classroom environment:

I like developing a full relationship with my students, and it is easier to do this when I also have relationships with their family members. We have more of a context for our relationship, and so my praise, expectations, constructive criticism, etc. seem more genuine to a student. I like that I can see my students as a whole child, and not just a science student.

Not only do teachers perceive the knowledge of all aspects of a student's life to be useful to them as educators, but they also perceive their relationship holds more weight in the eyes of their students. Teacher feedback is taken more seriously, and considered more important when deeper relationships exist.

Multiplex relationships are not, however, without their problems. While several teachers commented that they held no "dislikes" toward multiplex relationships, many teachers felt the deeper relationships blur the lines of professionalism with both students in classroom and extended families outside the classroom. For example, one teacher states:

I dislike when students get too comfortable around their teachers and forget to show due respect. I also dislike when students/parents use relationships to manipulate school professionals to get what they want.

The familiarity that comes with deep multiplex relationships is accompanied by a level of informality that many teachers find inappropriate in the context of the classroom and can lead to disciplinary issues. A second teacher explains, "The th[i]ng I do struggle with is there are times [students] do not behave like they should and at times they think the rules do not apply to them." Given the recorded frequencies, it appears that these issues are far outweighed by the advantages multiplex relationships afford students and teachers. However, they are not insignificant issues and illustrate the complexities of negotiating multiplex relationships in a rural context.

\section{Discussion and Implications}

While previous research suggests a positive impact on student performance by positive teacherstudent relationships (e.g. Roorda, et al., 2011), the data collected in this study with regard to RA and ITP scores in science do not support similar conclusions. There are a couple of possible explanations for this observation. First, it is possible that since data in this study were collected solely from the teachers' perspective, students did not associate multiplex relationships with an improved classroom environment, which has been shown to be associated with increased performance (McCormick, et al., 2013; Roorda, et al., 2011; Spilt et al., 2012). However, this did not hold true for teachers, who felt the knowledge of the "whole child" allowed them to tailor their instruction to individual students' needs and therefore affect student performance. Pedagogically, it appears that teachers perceive multiplex relationships to be quite beneficial.

A more likely explanation for the weak association between RA and ITP science scores is the unique context of rural science education where a standardized science curriculum - and standardized state test - do not accurately measure student science knowledge. Avery and Kassam (2011) found that $5^{\text {th }}$ and $6^{\text {th }}$-grade rural students had an extensive knowledge of science and engineering based on their experiences of helping their parents at home but were only able to connect that knowledge to their classroom assignments and activities when explicitly asked to try. As such, these connections and knowledge may not be readily accessible to students during a standardized exam heavily imbedded in academic language. This has significant implications and support for making rural education more "placebased" and relevant to students (Shamah \& MacTavish, 2009). However, it appears that the teachers in this study perceive the increased social capital that comes with multiplex relationships to be greatly beneficial to academic performance.

Goodpaster et al. (2012) showed multiplex relationships are unique to the rural education experience and states that multiplex relationships "enhance" various interactions, communications, and building with all members of the school and community. Participants of this study go a step beyond Goodpaster and overwhelmingly perceive that multiplex relationships have a positive influence on student success in the science classroom, despite the lack of evidence in the quantitative data. Instead, teachers' perceptions focus on the social capital gained through their relationships and how it allows them to alter their teaching. Teachers, from their perspective, often observe more effort or 
participation from a student due to a strong relationship established with the student. This coincides with social capital theory's model where the more contexts in which a relationship exists, a larger level of trust and reciprocity will be present which in turn, contributes to positive student outcomes (Carr, 2005; Hardré et al., 2008). Additionally, knowledge of individual student interests, extracurricular activities, personal life, and home life, is only available because the teacher has accrued the trust and social capital necessary to gain access to that knowledge. The more relationships a teacher has with a student outside the classroom, the tighter the network interconnectivity and higher the social capital. However, it may be that teachers are confounding the effect of multiplex relationships on achievement and the effect on their pedagogy.

Knowledge of the "whole child" that comes with a teacher's increased social capital allows them to better relate science content to their students. Making science relevant to students is a goal often touted in science education reform (NGSS Lead States, 2013), however, the examples for rural students are likely different than their urban and suburban counterparts (e.g. urban heat islands). Again, the argument for "place-based" education is relevant (Edmondson \& Butler, 2010; Howley et al., 2011; Shamah \& MacTavish, 2009) especially in light of the adoption of new science standards where phenomena from students' lives are used as the context for explaining science concepts (NGSS Lead States, 2013). The elevated levels of social capital allow teachers to nurture connections they have outside the classroom to involve members of the community from industry and commerce (Kenny, Seen, \& Pursor, 2008; Lake, 2008) and while the qualitative responses from our sample did not indicate our teachers utilized those resources in their classrooms, it may simply be a function of the fact that they were not asked to elaborate on that aspect of their pedagogy. Regardless, we perceive the increased social capital present in rural classrooms as an opportunity to bridge the academic language of science with the realities of rural students' lives.

Increased social capital, however, also appears to blur the lines of professionalism between teachers and their students as well as their students' parents. This is in line with social capital theory which states that reciprocity based on trust is generated (Coleman, 1988 ) in rural areas due to shared values (Elder \& Conger, 2000). This reciprocity is further heightened in rural areas due to multiplex relationships (Campbell \& Gordon, 2003; Goodpaster et al., 2012; Hargrove, 1986), but the reciprocity referred to in social capital theory is that of goods or services that take the form of norms and expectations in a school setting (Coleman, 1988), including time and productivity (Western et al., 2005). The request by students or parents for special consideration that our participants mention, appears to be a function of a more connected network and elevated social capital and consequently an expectation of reciprocity.

\section{Conclusion}

This study suggests that multiplex relationships do not directly influence student standardized test scores, and that an impactful teacher-student relationship does not necessarily come from teacherstudent interactions in multiple environments. However, the role multiplex relationships play for teachers in a rural education environment is much more substantial toward increasing their social capital and the difference they report in their teaching practices. This is likely why they perceive multiplex relationships affect the academic performance of their students.

The question remains as to why these changes in pedagogy do not ultimately affect achievement. The obvious answer may simply be in the chosen measure of achievement. Standardized test scores are certainly not the only measure of academic achievement, and previous studies on Teacher-Student relationships where academic benefits have been illustrated, mostly relied on course grades to demonstrate achievement (Roorda, et al. 2011). Additionally, Somers and coworkers (2011) caution against using state-based standardized tests as a sole measure of academic achievement, although their caution is more relevant to multi-state studies where the exams may differ from one another.

Since all data collected were self-reported, it is also possible that the differences teachers report in their teaching are perceived and are not as profound as they imagine. Self-reported data, especially with regard to teaching practices, is typically problematic (e.g Fang, 1996), however it was not the original intent of this study to closely examine teaching practices and only came about after analysis of teacher responses. Consequently, closer examination of actual teaching practices of rural teachers may shed further light on how social capital and multiplex relationships affect the rural classroom.

Additionally, the overall reported RA (mean = 1.53 ; median $=1.36$ ) represents an average number of relationships only slightly greater the context of the classroom $(\mathrm{RA}=1)$, which appears low given the rural nature of the participating schools. The relationships averages for teachers in urban and suburban schools were not measured as part of this study and so it is unknown if rural teachers indeed have higher RAs. Further studies involving 
populations with larger average RAs may be more useful in determining connections between academic achievement and RA.

Finally, since it was not an element of the original research questions, demographic data such as gender, socioeconomic status, and ethnicity were not specifically analyzed as factors of RA or ITP scores. However, each of these elements conceivably shape the rural environment and have the potential to affect a teacher perspective in multiplex relationships and the effect it has on student achievement. For example, according to census data, the only population growth the state of Iowa experienced over the past 25 years has been a result Latino immigration (Iowa State University Extension and Outreach, 2015). Statewide, Iowa experienced a $121.4 \%$ increase in its Latino population between 2000 and 2016 and is only projected to continue experience.
(State Data Center of Iowa, 2017). While this population growth occurs in both rural and urban counties across the state, the largest percentage increases are occurring in rural counties. For example, between 2000 and 2015 two rural counties in Iowa, Ringgold and Lyon, experienced an $892.3 \%$ and $638.1 \%$ increase in their Latino populations respectively. This speed and amount of demographic shift presumably affects relationships across the community and subsequently within the schools and is worthy of further examination.

Regardless, it is clear that rural science teachers value the multiplex relationships they have with their students and embrace a variety of aspects of the social capital build between them and their students. This mindset is seemingly widespread across the rural science teachers in this population and is the essence of the rural education

\section{References}

Alleman, N. F., \& Holly, L. N. (2013). Multiple points of contact: Promoting rural postsecondary preparation through school-community partnerships. The Rural Educator, 34(2). Retrieved from http://epubs.library.msstate.edu/index.php/rurale ducator/article/view/110

Aultman, L. P., Williams-Johnson, M. R., \& Schutz, P. A. (2009). Boundary dilemmas in teacherstudent relationships: Struggling with "the line". Teaching and Teacher Education, 25(5), 636646. doi:10.1016/j.tate.2008.10.002

Avery, L. M., \& Kassam, K. A. (2011). Phronesis: Children's local rural knowledge of science and engineering. Journal of Research in Rural Education, 26(2), 1-18.

Avery, L. M. (2013). Rural science education: Valuing local knowledge. Theory into Practice, 52(1), 28-35.

Barley, Z. A., \& Beesley, A. D. (2007). Rural school success: What can we learn? Journal of Research in Rural Education, 22(1), 1-16.

Bauch, P. A. (2001). School-community partnerships in rural schools: Leadership, renewal, and a sense of place. Peabody Journal of Education, 76(2), 204-221.

Berry, A. B., \& Gravelle, M. (2013). The benefits and challenges of special education positions in rural settings. The Rural Educator, 34(2), 25-37.

Brown, B. L. (2002). CTE organizations. ERIC Digest ED467238. Columbus, OH: Center on Education and Education for Employment. Retrieved July 26, 2014, from http://www.calproonline.org/ERIC/docs/dig235.pdf

Campbell, C. D. \& Gordon, M. C. (2003). Acknowledging the Inevitable: Understanding multiple relationships in rural practice. Professional Psychology: Research and Practice, 34(4), 430-434. doi:10.1037/07357028.34.4.430

Carr, D. (2005). Personal and interpersonal relationships in education and teaching: A virtual ethical perspective. British Journal of Educational Studies, 53(3), 255-271.

Coleman, J. S. (1988). Social capital in the creation of human capital. American Journal of Sociology, 94. S95-S120.

Colton, R. W. (1981). The science program in small rural secondary schools. ERIC Clearinghouse on Rural Education and Small Schools, Educational Resources Information Center, Las Cruces, NM. ED197913

Creswell, J. W. (2013). Research design: Qualitative, quantitative, and mixed methods approaches. Thousand Oaks, CA: Sage publications.

Edmondson, J., \& Butler, T. (2010). Teaching school in rural America: Toward an educated hope. In Schafft, K. A., \& Jackson, A. Y. (Eds), Rural education for the twenty-first century: Identity, place, and community in a globalizing world, (pp. 150-172). University Park, PA: Pennsylvania State University Press.

Elder, G. H., \& Conger, R. D. (2000). Children of the land: Adversity and success in rural America. Chicago, IL: University of Chicago Press. 
Fang, Z. (1996). A review of research on teacher beliefs and practices. Educational research, 38(1), 47-65.

Frankovits, N. D. (1990). To Build Confidence, To Improve Skills. In National Science Teachers' Association (Eds), Science \& math events: Connecting and competing, (pp. 7-11). Washington D.C.: National Academies Press.

Glaser, B. G., \& Strauss, A. L. (1967). The Discovery of Grounded Theory; Strategies for Qualitative Research Chicago: Aldine.

Gluckman, M. (1967). The judicial process among the Barotse of Northern Rhodesia, $2^{\text {nd }} \mathrm{Ed}$. Manchester, UK: Manchester University Press.

Goodpaster, K. P., Adedokun, O. A., \& Weaver, G. C. (2012). Teachers' perceptions of rural STEM teaching: Implications for rural teacher retention. The Rural Educator, 33(3), 9-22.

Gristy, C. (2012). The central importance of peer relationships for student engagement and wellbeing in a rural secondary school. Pastoral Care in Education, 30(3), 225-240.

Guest, A., \& Schneider, B. (2003). Adolescents' extracurricular participation in context: The mediating effects of schools, communities, and identity. Sociology of Education, 76, 89-109.

Hardré, P. L., Sullivan, D. W., \& Roberts, N. (2008). Rural teachers' best motivating strategies: A blending of teachers' and students' perspectives. The Rural Educator, 30(1), 19-31.

Hargrove, D. S. (1986). Ethical issues in rural mental health practice. Professional Practice: Research and Practice, 17(1), 20-23. doi:10.1037/07357028.17.1.20

Horn, J. G. (1995). What is rural education? In P. B. Otto (Ed), Science education in the rural United States: Implications for the twenty-first century. A yearbook of the Association for the Education of Teachers in Science (pp.12-25). Washington DC: Association for the Education of Teachers in Science.

Howley, A., Howley, M., Camper, C., \& Perko, H. (2011). Place based education at island community school. The Journal of Environmental Education, 42(4), 216-236. doi:10.1080/00958964.2011.556682

Huysman, J. T. (2008). Rural teacher satisfaction: An analysis of beliefs and attitudes of rural teachers' job satisfaction. The Rural Educator, 29(2), 3138.

Iowa Department of Education. (2015). 2014-2015

Iowa public school building PreK-12

enrollments by school, grade, race and gender. [Data file]. Retrieved February 16, 2018 from: https:/www.educateiowa.gov/documents/public- buildings-public/2015/03/2014-2015-iowapublic-school-building-prek-12-enrollment-0

Iowa State University Extension and Outreach (2015). A Snapshot of Rural Iowa. Retrieved Feb 8, 2018 from:

http://indicators.extension.iastate.edu/sites/defaul t/files/data/Iowa_Snapshot\%5B1\%5D.pdf

Kenny, J., Seen, A., $\&$ Purser, J. (2008). Supporting and resourcing secondary science teachers in rural and regional schools. Teaching Science, 54(3), 19-24.

Klem, A. M., \& Connell, J. P. (2004). Relationships matter: Linking teacher support to student engagement and achievement. Journal of School Health, 74(7), 262-273.

Lake, D. (2008). Perceptions of science in oneteacher schools. Teaching Science, 54(3), 36-43.

Lock, G. (2008). Preparing teachers for rural appointments: Lessons from Australia. The Rural Educator, 29(2), 24-30.

Ludden, A. B. (2011). Engagement in school and community civic activities among rural adolescents. Journal of Youth and Adolescents, 40, 1254-1270.

Matthew, K. L. (1995). Teaching and learning science in the rural setting. In P. B. Otto (Ed), Science education in the rural United States. Implications for the twenty-first century. A Yearbook of the association for the education of teacher in science (pp. 43-50). Washington DC: Association for the Education of Teachers in Science.

McCormick, M. P., O'Connor, E. E., Cappella, E., \& McClowry, S. G. (2013). Teacher-child relationships and academic achievement: A multilevel propensity score model approach. Journal of School Psychology, 51(5), 611-624. doi: 10.1016/j.jsp.2013.05.001

Miles, M. B., \& Huberman, A. M. (1994). Qualitative Data Analysis: An expanded sourcebook (2 ed.). Thousand Oaks: Sage.

National Center for Education Statistics. (2006). Identification of Rural Locales. Retrieved Feb. 16, 2016, from https://nces.ed.gov/ccd/rural_locales.asp

NGSS Lead States (2013). Next Generation Science Standards: For States, By States. Washington, DC: The National Academies Press.

Northwestern University (2016). Do your data violate one-way ANOVA assumptions? Retrieved Dec 2, 2016, from PROPHET StatGuide: http://www.basic.northwestern.edu/statguidefiles /oneway_anova_ass_viol.html

Osborn, A. (2012). Juggling personal life and professionalism: Ethical implications for rural 
school psychologists. Psychology in the Schools, 49(9), 876-882.

Phelps, K., Henry, A. L., \& Bird, W. A. (2012). Factors influencing of discouraging secondary school students' FFA participation. Journal of Agriculture Education, 53(2), 70-86. doi:10.5032/jae.2012.02070

Rayfield, J., Compton, K., Doerfert, D., \& Akers, C. (2008). Factors that influence the decision to particpate in youth organizations in rural high schools in three states. Journal of Agricultural Education, 49(4), 83-95.

Reyes, M. R., Brackett, M. A., Rivers, S. E., White, M., \& Salovey, P. (2012). Classroom emotional climate, student engagement, and academic achievement. Journal of Educational Psychology, 104(3), 700-712. doi: 10.1037/a0027268

Roberts, T. G., Dooley, K. E., Harlin, J. F., \& Murphrey, T. P. (2006). Competencies and traits of successful agricultural science teachers. Journal of Career and Technical Education, 22(2), 1-11.

Roorda, D. L., Koomen, H. M., Spilt, J. L., \& Oort, F. J. (2011). The influence of affective teacherstudent relationships on students' school engagement and achievement: A meta-analytic approach. Review of educational research, 81(4), 493-529. doi: 10.3102/0034654311421793

Shamah, D., \& MacTavish, K. A. (2009). Making room for place-based knowledge in rural classrooms. The Rural Educator, 30(2), 1-4.

Sipple, J. W., \& Brent, B. O. (2008). Challenges and strategies associated with rural school settings. In H. F. Ladd \& E. B. Fiske (Eds.), Handbook of Education Finance and Policy, (pp. 612-630). New York, NY: Routledge.
Somers, M. A., Zhu, P., \& Wong, E. (2011). Whether and how to use state tests to measure student achievement in a multi-state randomized experiment: An empirical assessment based on four recent evaluations. NCEE 2012-4015. U.S. Department of Education, National Center for Education Evaluation and Regional Assistance.

Spilt, J. L., Hughes, J. N., Wu, J. Y., \& Kwok, O. M. (2012). Dynamics of teacher-student relationships: Stability and change across elementary school and the influence on children's academic success. Child Development, 83(4), 1180-1195. doi: 10.1111/j.14678624.2012.01761.x

State Data Center of Iowa (2017). Latinos in Iowa: 2017 Retrieved Feb 8, 2018 from http://www.iowadatacenter.org/Publications/latin os2017.pdf

Tytler, R., Symington, D., Kirkwood, V., \& Malcolm, C. (2008). Engaging students in authentic science through school-community links: Learning from the rural experience. Teaching Science, 54(3), 13-18.

United States Department of Education. (2014). Rural education in America. Retrieved February 12, 2014, from National Center for Education Statistics: http://nces.ed.gov/surveys/ruraled/definitions.asp

Verbrugge, L. M. (1979). Multiplexity in adult friendships. Social Forces, 57(4), 1286-1309.

Voyles, M. (2012). Perceived needs of at-risk families in a small town: Implications for fullservice community schools. School Community Journal, 22(2), 31-63.

Western, J., Stimson, R., Baum, S., \& Von Gellecum, Y. (2005). Measuring community strength and social capital. Regional Studies, 39(8), 10951109.

\section{About the Authors:}

Peter Knutson, M.A. is the science curriculum coordinator for Dubuque Community Schools. He can be contacted atpknutson@dbqschools.org and pknut53@gmail.com.

Dawn Del Carlo, Ph.D. is a faculty member in the Chemistry and Biochemistry program and Graduate Coordinator in Science Education at the University of Northern Iowa. She can be contacted at dawn.delcarlo@uni.edu.

\section{Suggested Citation:}

Knutson, P., \& Del Carlo, D. (2018). Impact of multiplex relationships on rural science education. The Rural Educator, 39(2), 21-35. Retrieved from http://epubs.library.msstate.edu/index.php/ruraleducator 